\title{
OVARIAN STROMAL BLOOD FLOW AFTER LAPAROSCOPIC OVARIAN DRILLING IN WOMEN WITH POLYCYSTIC OVARY SYNDROME
}

\author{
Anwar E. Ismail; Mohamed N. Azzam; Gamal A. Al-Sayed and Mostafa A.A. Salem \\ Obstetrics and Gynecology Department, Faculty of Medicine, Zagazig University
}

\section{ABSTRACT}

Background: Women with polycystic ovary syndrome have significant difference in their ovarian stromal blood flow indices when compared to women with normal ovaries. The intra-ovarian blood flow is assessed by studying small arteries in the ovarian stroma not close to the surface of the ovary or near the wall of the follicles.

Aim: To assess the value of changes in Doppler indices of ovarian stromal blood flow and hormonal profile in women with PCOS and previously described as being clomiphene citrate resistant in predicting the clinical outcome of laparoscopic ovarian drilling as regard ovulation.

Study design: This study is interventional study.

Setting: Department of Obstetrics and Gynecology (Ultrasound and Gynecologic endoscopy units), Faculty of Medicine, Zagazig University.

Patients' criteria: Women with PCOS according to Rotterdam criteria, 2003, aged 18-35 years. All women in the study were free of any medical illness and had not received any medications in the last 6 months before the study apart from incremental doses of clomiphene citrate with its failure to induce ovulation in them (clomiphene citrate resistant). Hysterosalpingography and husband semen analysis were normal in all subjects.

Sample size: 59 PCOS patients.

Procedures: After measuring peak systolic blood flow velocity (PSV), pulsatility index (PI) and resistance index (RI) within the ovarian stroma using two dimensional colour Doppler transvaginal sonography and measuring the serum concentrations of FSH, LH and total testosterone of 59 PCOS patients, laparoscopic ovarian drilling was done (4 punctures in each ovary using 40 watts monopolar electrocautery for 4 seconds). Ovulation was evaluated by serial ultrasound and mid luteal serum progesterone level in the first post-operative menstruation.

Results: Within 10 weeks of laparoscopic ovarian drilling (LOD), LH decreased significantly from (13.1 \pm 1.9$)$ before LOD to $(6 \pm 0.6)$ after LOD and total testosterone decreased significantly from $(1.04 \pm 0.23)$ to $(0.51 \pm 0 . \overline{2})$. As regard FSH, it increased significantly from $(6.16 \pm 0.34)$ before LOD to $(7.6 \pm 0.8)$ after LOD. PSV decreased significantly from $(11.9 \pm 1.8)$ before LOD to $(7.44 \pm 1.5)$ after LOD. Also, PI increased significantly from $(2.02 \pm 0.56)$ before LOD to $(2.98 \pm 0.5)$ after LOD. As regard RI, it increased significantly from $(0.75 \pm 0.06)$ before LOD to $(0.86 \pm 0.05)$ after LOD. There was significant negative correlation between total testosterone and PI $(\mathrm{r}=0.49, \mathrm{p}$. value $<0.01)$, highly significant negative correlation between total testosterone and RI $(\mathrm{r}=0.41$, p. value $<0.001)$ and significant positive correlation between total testosterone and PSV $(r=0.32, \mathrm{p}$. value $<0.05)$. Conclusion(s): PCOS patients to whom Laparoscopic ovarian drilling was done usually experienced reduction in their blood flow within the ovarian stroma. There was statistically significant correlation between hormonal profile and changes in the blood flow within the ovarian stroma in those patients. This may be valuable in predicting the clinical outcome of LOD as regard ovulation and pregnancy.

Key Words: Ovarian stromal blood flow, laparoscopic ovarian drilling, Doppler, polycystic ovary syndrome.

\section{INTRODUCTION}

$\mathbf{P}$ olycystic ovary syndrome (PCOS) is the most common endocrinopathy in females in their childhood bearing period and the main etiology of infertility due to anovulation, affecting more than $70 \%$ of cases ${ }^{(1)}$, and affecting $5 \%-10 \%$ of females in their childhood bearing period ${ }^{(2)}$.

The diagnosis of this syndrome according to the Rotterdam criteria, 2003 include any two of the following three criteria: (1) oligo-ovulation and/or anovulation; (2) clinical and/or biochemical manifestations of androgen excess; and (3) polycystic ovaries using transvaginal sonography; after exclusion of other etiologies of androgen excess such as congenital adrenal hyperplasia, androgen secreting tumors and Cushing's syndrome ${ }^{(3)}$.

There is recent interest regarding the possible role of two dimensional (2D) transvaginal color Doppler ultrasound in evaluating the blood flow within the ovarian stroma in PCOS patients. Those PCOS patients have considerable difference in the blood flow within the ovarian stroma when compared to females with healthy ovaries. The blood flow within the ovarian stroma is measured by evaluating the vasculature of the ovarian stroma (small arteries within the stroma of the ovary away from the surface of the ovary and the wall of the follicles) ${ }^{(4)}$.

A primary disorder within those ovaries most probably causes significant difference in the blood flow within the ovarian stroma ${ }^{(5)}$. Those PCOS patients when comparing them with healthy females not suffering from PCOS have an increased blood flow within the ovarian stroma in the early follicular phase of their menstruation ${ }^{(5,}$ ${ }^{6}$. This high ovarian stromal blood flow velocity occurs also after pituitary suppression with GnRH 
analogues and after controlled ovarian stimulation in females performing in-vitro fertilization ${ }^{(7)}$.

Clomiphene citrate (CC) is the classic first line used in ovulation induction in PCOS patients with ovulation rate $70-80 \%$ and pregnancy rate $40 \%$. Women who fail to ovulate with increased doses of CC are considered CC-resistant ${ }^{(8)}$.

The second line for ovulation induction in PCOS patients and are described as being CCresistant has been the subject of much debate, with competition between ovarian drilling, gonadotrophin and metformin ${ }^{(9,10)}$.

Ovarian drilling by laparoscopy (LOD) is considered an alternative treatment for CCresistant PCOS patients and has multiple benefits when compared to gonadotrophin therapy such as mono-ovulation, no risk of ovarian hyperstimulation syndrome, no increase in the incidence of multiple pregnancies, less cost and does not require intensive monitoring. In those patients, LOD results in ovulation in about $80 \%$ of patients and pregnancy in about 50\%-60\% of patients ${ }^{(11,12,13)}$.

Although the mechanism of action of LOD in PCOS patients has not yet been explored, one possible mechanism of action is that LOD decreases the production of androgen by the ovarian stroma, which in turns suppress the development and the growth of the ovarian follicles ${ }^{(4)}$. A very rapid response has been reported following laparoscopic ovarian drilling in several studies, with ovulation occurring within 24 weeks and menstruation within 4-6 weeks in the responders ${ }^{(14)}$.

Women are considered to have failed after laparoscopic ovarian drilling if they :(1) do not ovulate within 6-8 weeks; (2) experience recurrence of the anovulatory status after an initial response; and (3) fail to conceive despite regular ovulation for 12 months ${ }^{(15)}$.

The effect of laparoscopic drilling on the ovarian stromal blood flow indices in PCOS patients has not yet been evaluated by sufficient studies. Parsanezhad et al., 2003, Amin et al., 2003 and $\mathrm{Wu}$ et al., 2004 concluded that ovarian stromal blood flow velocity is decreased after LOD ${ }^{(4,16,17)}$, but Vizer et al., 2007 showed in their study that ovarian stromal blood flow velocity is increased after this procedure ${ }^{(\mathbf{1 8})}$, so more researches should be done to explore the relation between LOD, ovarian stromal blood flow and ovarian steroidogenesis ${ }^{(\mathbf{1 9})}$.

Evaluation of blood flow velocity within the ovarian stroma before and after LOD may be the best way to study the effects of this procedure, its mechanism of action on the ovaries ${ }^{(4)}$.
The aim of this work is to compare blood flow velocity within the ovarian stroma and hormonal profile before and after laparoscopic ovarian drilling in polycystic ovarian syndrome patients, previously described as being clomiphene citrate resistant and to explore the values of those parameters in predicting the clinical outcome of this line of management as regard ovulation and pregnancy.

\section{PATIENTS AND METHODS}

Patients:

This study was carried out in the Department of Obstetrics and Gynecology (Ultrasound and Gynecologic endoscopy units), Faculty of Medicine, Zagazig University from August 2011 to August 2013. The study included 59 infertile women with PCOS attended the infertility outpatient clinic and fulfilled the following criteria:

\section{Inclusion criteria:}

Patients' ages 18 to 35 years.

All patients were infertile (primary or secondary infertility) and were diagnosed as PCOS according to Rotterdam criteria, 2003 (two criteria are sufficient for diagnosis of PCOS: (i) oligo-and/or an-ovulation; which is manifested clinically by secondary amenorrhoea or oligomenorrhoea, (ii) androgen excess (clinical and/or biochemical); (hirsutism and/or elevated serum level of total testosterone), (iii) polycystic ovaries (should present in all cases) by ultrasonography (each ovary contains $\geq 12$ follicles each follicle about $2-9 \mathrm{~mm}$ and/ or ovarian volume more than $10 \mathrm{ml}$ ), and previous history of anovulation by transvaginal sonography while taking increased doses of clomiphene citrate (clomiphene citrate resistant).

- All women in the study were free of any medical illness and had not received any medications in the last 6 months before the study apart from clomiphene citrate with its failure to induce ovulation in them. They were diagnosed by their doctors as being clomiphene citrate resistant after they received $50 \mathrm{mg} \mathrm{CC}$ in the $1^{\text {st }}$ month for 5 days starting from the $3^{\text {rd }}$ day of the menstrual cycle, 100 $\mathrm{mg}$ in the $2^{\text {nd }}$ month and $150 \mathrm{mg}$ for 4 months (they received $\mathrm{CC}$ for 6 months) with no evidence of ovulation.

- Hysterosalpingography and husband semen analysis were normal in all subjects.

\section{Exclusion criteria:}

- Other PCOS like syndromes (late onset congenital adrenal hyperplasia-androgen 
producing tumors-Cushing's syndrome), hyperprolactinemia and thyroid abnormalities.

- Gross ovarian pathology either diagnosed preoperatively by ultrasound or intraoperatively by laparoscopy.

- Any uterine pathology diagnosed preoperatively by ultrasound or intraoperatively by endoscopy and suspected to cause infertility.

- Other causes of infertility even if diagnosed during laparoscopy such as tubal pathology and pelvic endometriosis or adhesions.

- Previous tubal or ovarian surgery.

- Contraindications to laparoscopy and general anaethesia.

- Pregnancy before the first post-operative menstrual cycle.

Type of study:

This study is a Quasi Experimental study.

\section{Ethical considerations:}

The study protocol was approved by the local Ethical Committee of Faculty of Medicine, Zagazig University. An informed written consent was taken from all patients and their husbands before starting the study and every patient had the right to leave the study at any time.

Methods:

The following was done:

- A full detailed history was taken from all patients

- General examination.

- Abdominal examination.

- Local examination.

- Ultrasound: Transabdominal and/or transvaginal ultrasound to exclude patients with ovarian masses or pelvi-abdominal masses. Other investigations were done to fulfill the inclusion and exclusion criteria (serum prolactin level, free T3, free T4, TSH).

- Hormonal profile: Serum levels of LH, FSH and total testosterone were measured in the early follicular phase (days 2-4 of spontaneous cycle in oligomenorrhic patients). To start the study in amenorrhic patients (after exclusion of pregnancy) they received progesterone (oral Norethisterone acetate $10 \mathrm{mg}$ daily for 5 days) to induce withdrawal bleeding and hormonal profile was measured in days 2-4 of this withdrawal bleeding. Hormonal assay was done for all patients in the Laboratory of Zagazig University Hospitals by Electrochemiluminescence (ECL) technology
(Cobas e 411 analyzer-Roche Diagnostics GmbH-D-68298 Mannheim-Germany).

- Doppler study: Transvaginal 2D color Doppler probe of Voluson 730 pro $\mathrm{V}$ machine (GE healthcare, Austria with a $3.5 \mathrm{MHz}$ sector transducer for TAS and $7.5 \mathrm{MHz}$ sector transducer for TVS) was used. While the patients at lithotomy position after they had evacuated their urinary bladder and on the same days of the hormonal assay, baseline 2D TVS was used to examine the uterus for any abnormality and measuring the uterine size and endometrial thickness and then to identify PCO criteria in both ovaries and ovarian volume was measured using ellipisoid prolate formulae (length $\mathrm{X}$ width $\mathrm{X}$ height $\mathrm{X} 0.523$, which is calculated automatically by the software of the ultrasound machine) (each ovary contains $\geq 12$ follicles measuring $2-9 \mathrm{~mm}$ and/ or ovarian volume more than $10 \mathrm{ml}$ ) then color Doppler ultrasound scanning was performed to assess the ovarian stromal blood flow. Both ovaries were analyzed in each PCOS patient using color and power Doppler ultrasonound. Using colour and power Doppler, colour signals were searched for along the ovarian stroma away from the ovarian surface and away from the wall of the follicles. Areas of maximum colour intensity were visualized and selected for pulsed Doppler. The mean value for all ovarian blood flow parameters was calculated and used in the statistical analysis as there was no statistical significance in Doppler parameters of ovarian stromal arteries between the right and left ovaries.

- Laparoscopic ovarian drilling was performed under general anesthesia with good muscle relaxation and endotracheal intubation using the three-punctures technique (one puncture $10 \mathrm{~mm}$ at the umbilicus and the other two punctures $5 \mathrm{~mm}$ at both iliac fossa) in the early follicular phase (after stoppage of menstrual or withdrawal bleeding). After exclusion of any pelvic pathology, the ovaries were evaluated for polycystic ovary criteria (bilateral ovarian enlargement with smooth glistening surface unbroken by the usual wrinkles and thick, smooth, whitish capsule). Methylene blue test was done for all patients to examine the tubal patency and bilateral tubal patency was mandatory before ovarian drilling. A specially designed monopolar electrocautery probe was used to penetrate the ovarian capsule at 4 points $^{(20)}$ (regardless of the size of the ovary), with the aid of a short burst of monopolar 
diathermy. The probe was applied to the surface of the ovary at a right angle to avoid slippage and to decrease surface thermal damage. A monopolar coagulating current at a 40 Watts was used. The needle was inserted into the ovarian capsule for about $4 \mathrm{~mm}$ depth into the ovarian tissue and electricity was activated for 4 seconds ${ }^{(19)}$. The ovaries were washed using $250 \mathrm{ml}$ crystalloid solution then the ligament is released.

Follow up:

1- Hormonal assay (FSH - LH - total testosterone) was performed three times after LOD fone and two weeks after drilling and also, in the early follicular phase (days 2-4 of the menstrual cycle) of the first post-operative spontaneous menstruation (which occurred within 10 weeks after the operation)\}. In non-menstruating patients, the third hormonal profile reading was performed by the end of the 10 weeks. The mean of the three readings of $\mathrm{FSH}, \mathrm{LH}$ and total testosterone was calculated used in the final statistical analysis.

2- Blood flow assessment (PSV - PI - RI) was performed once after LOD \{in the early follicular phase (days 2-4 of the menstrual cycle) of the first post-operative spontaneous menstruation (which occurred within 10 weeks after the operation) \}. In non-menstruating patients, the blood flow assessment was performed by the end of the 10 weeks.

3- In menstruating patients, the cycle was evaluated for hormonal profile, blood flow within the ovarian stroma and also for ovulation detection.

4- Ovulation was assessed by serial transvaginal ultrasound until seeing pre-ovulatory follicle $\geq 18$ $\mathrm{mm}^{(\mathbf{2 1})}$. Ovulation was confirmed by visualization of follicle collapse on subsequent transvaginal ultrasound, appearance of fluid in the Douglas pouch and elevated mid-luteal serum progesterone level $>5 \mathrm{ng} / \mathrm{ml}^{(4)}$. Ovulating group was informed to report the occurrence of natural conception for 6 months after LOD.

5- Patients who did not menstruate (pregnancy should be excluded) or did not ovulate within 10 weeks after drilling as evidenced by poor follicular growth by serial transvaginal ultrasound folliculometry, and low mid-luteal serum progesterone level $<5 \mathrm{ng} / \mathrm{ml}$ were referred to another group of researchers for re-evaluation.

\section{Statistical analysis:}

The relationship between ovarian stromal blood flow indices and hormonal profile changes before and after laparoscopic ovarian drilling
(LOD) was examined by the Paired t-test. Paired t-test was used to compare mean values.

Statistical tests used in the present study were conducted, using the mean, standard deviation, t-test, X2 by SPSS 14.0.

\section{RESULTS}

In this interventional study, 59 patients were included; however 9 cases were excluded from the statistical analysis because they did not complete the measurements. Therefore, 50 patients were used for the final analysis. All patients were infertile \{primary (48\% of cases) or secondary (52\% of cases) $\}$ and diagnosed as PCOS according to the Rotterdam 2003 concession \{two criteria are sufficient for the diagnosis of PCOS: 1- Anovulation which was manifested clinically by oligomenorrhea (50\% of cases) \{cycle length in this group ranged from 6 to 10 weeks $\}$ or secondary amenorrhea (50\% of cases) \{no menses for three consecutive cycles (more than 12 weeks amenorrhea)\}. 2- Hyperandrogenism \{hirsutism(66\% of cases were suffering from hirsutism and $34 \%$ were not) and/or high total testosterone level\}. 3-Polycystic ovaries (present in all cases) by ultrasonography.

All patients were followed up for 10 weeks to detect the outcome of the laparoscopic ovarian drilling as regard recurrence of menstruation and occurrence of ovulation. The ovulating group was asked to note pregnancy during 6 months of follow up after LOD.

There were non-significant differences between ovulating patients and non-ovulating patients as regard age, BMI and duration of infertility as shown in table (1).

Menstrual cycle pattern, type of infertility and hirsutism did not significantly affect the results of this study as shown in table (2).

There was non-significant difference between ovulating patients and non-ovulating patients as regard ovarian volume as shown in table (3).

In table (4), there were non-significant differences between ovulating and non-ovulating patients as regard serum total testosterone, FSH and LH levels before LOD and high significant differences as regard serum total testosterone, FSH and LH levels between both groups after LOD.

In table (5), there were non-significant differences between ovulating and non-ovulating patients as regard peak systolic velocity, pulsatility index and resistance index before LOD and high-significant differences as regard peak systolic velocity, pulsatility index and resistance index between both groups after LOD. 
In table (6) there was a non- significant difference between patients with slightly increased ovarian volume and patients with markedly increased ovarian volume as regard Doppler indices.

Correlation between hormonal changes (FSHLH- total testosterone) and Doppler changes (PSV- PI- RI) after LOD in ovulating group are shown in table (7). Total testosterone showed:
1- Significant negative correlation with PI ( $\mathrm{r}=$ 0.49 , p. value $<0.01)$.

2- Significant positive correlation with $\operatorname{PSV}(\mathrm{r}=$ o.32, p. value <0.05).

3- Highly significant negative correlation with RI $(\mathrm{r}=0.41, \mathrm{p}$. value $<0.001)$. Also, FSH showed a significant positive correlation with $\mathrm{RI}(\mathrm{r}=0.32 \mathrm{p}$. value $<0.05)$.

Table (1): Comparison between ovulating and non-ovulating patients as regard age, body mass index and duration of infertility:

\begin{tabular}{|c|c|c|c|c|}
\hline Characteristics & Ovulating & Non-ovulating & t. test & p. value \\
\hline \multicolumn{5}{|l|}{ Age (years) } \\
\hline Mean \pm SD & $26.3 \pm 5.1$ & $26.8 \pm 4.8$ & \multirow[b]{2}{*}{0.34} & \\
\hline Range & 18-35 & 19-34 & & $\begin{array}{r}\mathbf{0 . 7 2} \\
(\mathbf{N} . S)\end{array}$ \\
\hline \multicolumn{5}{|l|}{ BMI (kg/m2) } \\
\hline Mean \pm SD & $26.9 \pm 3.4$ & $26.9 \pm 2.4$ & \multirow[t]{2}{*}{0.19} & \multirow{2}{*}{$\begin{array}{c}0.84 \\
\text { (N.S) }\end{array}$} \\
\hline Range & $21.5-32.7$ & $23.1-30.8$ & & \\
\hline \multicolumn{5}{|c|}{$\begin{array}{c}\text { Duration of infertility } \\
\text { (years) }\end{array}$} \\
\hline Mean $\pm S D$ & $3.98 \pm 1.7$ & $3.97 \pm 1.3$ & 0.03 & 0.96 \\
\hline Range & $1.5-6.5$ & $2-6$ & & (N.S) \\
\hline
\end{tabular}

Table (2): Comparison between ovulating and non - ovulating patients as regard menstrual cycle pattern, type of infertility and hirsutism:

\begin{tabular}{|c|c|c|c|c|c|}
\hline Characteristics & $\begin{array}{r}\text { Ovulating } \\
(\mathbf{N})\end{array}$ & $\begin{array}{c}\text { Non- ovulating } \\
(\mathbf{N})\end{array}$ & Total & $\mathbf{X} 2$ & P. value \\
\hline \multicolumn{6}{|l|}{ Menstrual cycle pattern } \\
\hline Secondary amenorrhea & $18(51.4 \%)$ & $7(46.7 \%)$ & 25 & \multirow{3}{*}{0.1} & \multirow{3}{*}{$\begin{array}{c}0.75 \\
\text { (N.S) }\end{array}$} \\
\hline Oligomenorrhea & $17(48.6 \%)$ & $8(53.3 \%)$ & 25 & & \\
\hline Total & 35 & 15 & 50 & & \\
\hline \multicolumn{6}{|l|}{ Type of infertility } \\
\hline Primary & $17(48.6 \%)$ & $7(46.7 \%)$ & 24 & \multirow{3}{*}{0.02} & \multirow{3}{*}{$\begin{array}{c}0.9 \\
(\mathbf{N S})\end{array}$} \\
\hline Secondary & $18(51.4 \%)$ & $8(53.3 \%)$ & 26 & & \\
\hline Total & 35 & 15 & 50 & & \\
\hline \multicolumn{6}{|l|}{ Hirsutism } \\
\hline (+ve) hirsutism & $23(65.7 \%)$ & $10(66.7 \%)$ & 33 & & \multirow{3}{*}{$\begin{array}{c}0.99 \\
\text { (N.S) }\end{array}$} \\
\hline (-ve) hirsutism & $12(34.3 \%)$ & $5(33.3 \%)$ & 17 & 0.01 & \\
\hline Total & 35 & 15 & 50 & & \\
\hline
\end{tabular}


Table (3): Comparison between ovulating and non-ovulating patients as regard ovarian volume:

\begin{tabular}{|c|c|c|c|c|c|c|c|}
\hline \multirow{2}{*}{$\begin{array}{c}\text { Ovarian } \\
\text { volume }\end{array}$} & \multicolumn{2}{|c|}{ Ovulating } & \multicolumn{2}{|c|}{ Non-ovulating } & \multirow[t]{2}{*}{ TOTAL } & \multirow[t]{2}{*}{$\chi^{2}$} & \multirow[t]{2}{*}{ p. value } \\
\hline & $\overline{\mathbf{N}}$ & $\%$ & $\mathbf{N}$ & $\%$ & & & \\
\hline $\begin{array}{c}\text { Slightly } \\
\text { increased } \\
\text { ovarian volume } \\
(10-12 \text { ml }) \\
8 \text { cases }(16 \%) \\
\end{array}$ & 6 & 17.1 & 2 & 13.3 & 8 & & \\
\hline $\begin{array}{c}\text { Markedly } \\
\text { increased } \\
\text { ovarian volume } \\
(>20 \mathrm{ml}) \\
42 \text { cases }(84 \%)\end{array}$ & 29 & 82.9 & 13 & 86.7 & 42 & 0.11 & $\begin{array}{c}0.74 \\
\text { (N.S) }\end{array}$ \\
\hline TOTAL & & 5 & & & 50 & & \\
\hline
\end{tabular}

Table (4): Comparison between ovulating and non-ovulating patients as regard serum total testosterone (ng/ml), FSH and LH (mIU/ml) level before and after LOD:

\begin{tabular}{|c|c|c|c|}
\hline $\begin{array}{l}\text { Total testosterone } \\
\text { (ng/ml) }\end{array}$ & $\begin{array}{c}\text { Before LOD } \\
\text { Mean } \pm \text { SD } \\
\text { Range }\end{array}$ & $\begin{array}{c}\text { After LOD } \\
\text { Mean } \pm \text { SD } \\
\text { Range }\end{array}$ & p. value \\
\hline Ovulating & $\begin{array}{c}1.04 \pm 0.23 \\
0.73-1.49\end{array}$ & $\begin{array}{c}0.51 \pm 0.2 \\
0.26-0.88\end{array}$ & $<0.001$ \\
\hline Non-ovulating & $\begin{array}{c}1.08 \pm 0.27 \\
0.76-1.5\end{array}$ & $\begin{array}{c}0.96 \pm 0.23 \\
0.69-1.3\end{array}$ & $\begin{array}{l}\text { 0.08 } \\
\text { (NS) }\end{array}$ \\
\hline t. test & 0.59 & 7.06 & \\
\hline p. value & $\begin{array}{l}\mathbf{0 . 5 5} \\
(\mathrm{NS}) \\
\end{array}$ & $<0.001$ & \\
\hline FSH (mIU/ml) & $\begin{array}{c}\text { Before LOD } \\
\text { Mean } \pm \text { SD } \\
\text { Range } \\
\end{array}$ & $\begin{array}{c}\text { After LOD } \\
\text { Mean } \pm \text { SD } \\
\text { Range } \\
\end{array}$ & p. value \\
\hline Ovulating & $\begin{array}{l}6.16 \pm 0.34 \\
4.41-6.99 \\
\end{array}$ & $\begin{array}{l}7.6 \pm 0.8 \\
5-8.99 \\
\end{array}$ & $<0.001$ \\
\hline Non-ovulating & $\begin{array}{r}5.9 \pm 0.87 \\
4.51-7.45 \\
\end{array}$ & $\begin{array}{c}6.1 \pm 0.9 \\
4.3-7.26 \\
\end{array}$ & $\begin{array}{l}\mathbf{0 . 0 7} \\
\text { (NS) }\end{array}$ \\
\hline t. test & 1.41 & 5.9 & \\
\hline p. value & $\begin{array}{l}\mathbf{0 . 1 6} \\
(\mathrm{NS}) \\
\end{array}$ & $<0.001$ & \\
\hline LH(mIU/ml) & $\begin{array}{c}\text { Before LOD } \\
\text { Mean } \pm \text { SD } \\
\text { Range } \\
\end{array}$ & $\begin{array}{c}\text { After LOD } \\
\text { Mean } \pm \text { SD } \\
\text { Range } \\
\end{array}$ & p. value \\
\hline Ovulating & $\begin{array}{c}13.1 \pm 1.9 \\
10-16\end{array}$ & $\begin{array}{c}6 \pm 0.6 \\
5.11-6.99 \\
\end{array}$ & $<0.001$ \\
\hline Non-ovulating & $\begin{array}{c}12.5 \pm 2.1 \\
10-16\end{array}$ & $\begin{array}{l}11.6 \pm 2.4 \\
7.8-16.7\end{array}$ & $\begin{array}{l}0.06 \\
\text { (NS) } \\
\end{array}$ \\
\hline t. test & 0.89 & 12.8 & \\
\hline p. value & $\begin{array}{l}\mathbf{0 . 3 7} \\
\text { (NS) }\end{array}$ & $<0.001$ & \\
\hline
\end{tabular}


Table (5): Comparison between ovulating and non-ovulating patients as regard peak systolic velocity, pulsatility index and resistance index before and after LOD:

\begin{tabular}{|c|c|c|c|}
\hline PSV $(\mathrm{cm} / \mathrm{s})$ & $\begin{array}{c}\text { Before LOD } \\
\text { Mean } \pm \text { SD } \\
\text { Range }\end{array}$ & $\begin{array}{c}\text { After LOD } \\
\text { Mean } \pm \text { SD } \\
\text { Range }\end{array}$ & p. value \\
\hline Ovulating & $\begin{array}{c}11.9 \pm 1.8 \\
8.9-14.77\end{array}$ & $\begin{array}{c}7.44 \pm 1.5 \\
4.89-10.08\end{array}$ & $<0.001$ \\
\hline Non-ovulating & $\begin{array}{l}12 \pm 2.48 \\
7.99-15\end{array}$ & $\begin{array}{c}10 \pm 3 \\
6-15.5\end{array}$ & $\begin{array}{l}0.06 \\
(\mathrm{NS})\end{array}$ \\
\hline t. test & 0.13 & 4.2 & \\
\hline p. value & $\begin{array}{r}\mathbf{0 . 8 9} \\
(\mathrm{NS}) \\
\end{array}$ & $<0.001$ & \\
\hline PI & $\begin{array}{c}\text { Before LOD } \\
\text { Mean } \pm \text { SD } \\
\text { Range }\end{array}$ & $\begin{array}{c}\text { After LOD } \\
\text { Mean } \pm \text { SD } \\
\text { Range }\end{array}$ & p. value \\
\hline Ovulating & $\begin{array}{l}2.02 \pm 0.56 \\
1.08-2.89\end{array}$ & $\begin{array}{c}2.98 \pm 0.5 \\
2.05-3.78\end{array}$ & $<0.001$ \\
\hline Non-ovulating & $\begin{array}{c}1.92 \pm 0.3 \\
1.08-2.35\end{array}$ & $\begin{array}{c}2.2 \pm 0.3 \\
1.79-2.8\end{array}$ & $\begin{array}{l}0.16 \\
\text { (NS) }\end{array}$ \\
\hline t. test & 0.64 & 5.57 & \\
\hline p. value & $\begin{array}{l}0.51 \\
(\mathrm{NS})\end{array}$ & $<0.001$ & \\
\hline $\mathbf{R I}$ & $\begin{array}{l}\text { Before LOD } \\
\text { Mean } \pm \text { SD } \\
\text { Range }\end{array}$ & $\begin{array}{c}\text { After LOD } \\
\text { Mean } \pm \text { SD } \\
\text { Range }\end{array}$ & p. value \\
\hline Ovulating & $\begin{array}{l}0.75 \pm 0.06 \\
0.65-0.85\end{array}$ & $\begin{array}{l}0.86 \pm 0.05 \\
0.77-0.95\end{array}$ & $<0.001$ \\
\hline Non-ovulating & $\begin{array}{l}0.7 \pm 0.07 \\
0.54-0.8\end{array}$ & $\begin{array}{c}0.8 \pm 0.1 \\
0.57-0.83\end{array}$ & $\begin{array}{l}0.18 \\
(\mathrm{NS})\end{array}$ \\
\hline t. test & 1.59 & 4.07 & \\
\hline p. value & $\begin{array}{l}0.11 \\
(\mathrm{NS})\end{array}$ & $<0.001$ & \\
\hline
\end{tabular}


Table (6): Relationship between ovarian volume and Doppler indices:

\begin{tabular}{|c|c|c|c|c|}
\hline $\begin{array}{c}\text { Doppler } \\
\text { indices }\end{array}$ & $\begin{array}{c}\text { Slightly increased } \\
\text { ovarian volume }(10-12 \\
\text { ml) } \\
8 \text { cases }(16 \%)\end{array}$ & $\begin{array}{c}\text { Markedly increased } \\
\text { ovarian volume( }>20 \\
\text { ml) } \\
42 \text { cases }(84 \%)\end{array}$ & t. test & p. value \\
\hline $\begin{array}{l}\text { PSV } \\
\text { Mean } \pm \text { SD }\end{array}$ & $11.6 \pm 1.5 \mathrm{~cm} / \mathrm{s}$ & $11.7 \pm 2.18 \mathrm{~cm} / \mathrm{s}$ & 0.12 & 0.9(N.S) \\
\hline $\begin{array}{l}\text { PI } \\
\text { Mean } \pm \text { SD }\end{array}$ & $1.62 \pm 0.41$ & $1.77 \pm 0.32$ & 1.2 & 0.25 (N.S) \\
\hline $\begin{array}{l}\text { RI } \\
\text { Mean } \pm \text { SD }\end{array}$ & $0.71 \pm 0.05$ & $0.74 \pm 0.04$ & 1.9 & 0.06(N.S) \\
\hline
\end{tabular}

Table (7): Correlation between hormonal profile and Doppler indices changes after LOD in ovulating group ( $\mathrm{r}=$ correlation coefficient and $\mathrm{D}=$ difference between values before and after LOD):

\begin{tabular}{ccccccccc}
\hline & \multicolumn{2}{c}{ D-PSV } & \multicolumn{1}{c}{ D-PI } & \multicolumn{2}{c}{ D-RI } \\
& r & p & r & p & r & p \\
\hline D-FSH & 0.22 & $>0.05$ & 0.18 & $>0.05$ & 0.32 & $<0.05$ \\
& & & & & & \\
\hline D-LH & 0.21 & $>0.05$ & 0.1 & $>0.01$ & 0.47 & $>0.05$ \\
\hline D-Total testosterone & 0.32 & $<0.05$ & -0.49 & $<0.01$ & -0.41 & $<0.001$ \\
\hline
\end{tabular}

Table (8): Pregnancy rate in ovulating group during 6 months of follow up after LOD:

After LOD Ovulating group ( 35 cases)

\begin{tabular}{ccc}
\hline $\begin{array}{c}\text { Pregnancy rate } \\
\text { during } 6 \text { months } \\
\text { of follow up after }\end{array}$ & 20 cases became pregnant & 15 cases did not become pregnant \\
LOD & $(57 \%)$ & $(43 \%)$ \\
\hline
\end{tabular}

As regard recurrence of menstruation; 40 patients $(80 \%)$ showed spontaneous menstruation $\{$ (within 3 weeks+ 1 day) to (7 weeks+ 6 days) after LOD), while 10 patients (20\%) did not menstruate during the follow up period (10 weeks).

As regard occurrence of ovulation:

1- 35 cases $(70 \%)$ showed ovulation as evidenced by folliculometry (leading follicular diameter $\geq 18$ $\mathrm{mm}$ followed by seeing follicle collapse on subsequent transvaginal ultrasound, appearance of fluid in Douglas pouch) and elevated mid luteal serum progesterone level ( $>5 \mathrm{ng} / \mathrm{ml}$ ).

2- 15 cases $(30 \%)$ did not show ovulation as evidenced by poor follicular growth by serial transvaginal ultrasound folliculometry (5 cases menstruated during the follow up period but did not ovulate) and low mid-luteal serum progesterone level $(<5 \mathrm{ng} / \mathrm{ml})$, or lack of menstruation $\{10$ cases ( 5 patients were belonging to the secondary amenorrhea group and the other 5 patients were belonging to the oligomenorrhea group)\}.

As regard occurrence of natural conception in ovulating group during 6 months of follow up after LOD, 20 cases became pregnant $57 \%$ of the ovulating patients - $40 \%$ of the whole number of cases in our study) and 15 patients did not become pregnant ( $43 \%$ of the ovulating patients-30\% of the whole number of cases in our study). This is shown in tab (8).

\section{DISCUSSION}

In our study we included cases of PCOS which had polycystic ovaries by 
ultrasounography. So, we included cases with frank PCOS (hyperandrogenism -chronic anovulation-polycystic ovaries by ultrasound) and cases with mild PCOS (chronic anovulationpolycystic ovaries by ultrasound). Cases with ovulatory PCOS were not included as there are ovulating and not need ovulation induction. Also cases with classic PCOS were excluded as they had normal ovaries and we believe that LOD could be used as a method of ovulation induction only in patients with polycystic ovaries not in patients with normal ovaries.

In our study we investigated various clinical and biochemical factors that may predict the outcome of LOD. Age, BMI, duration of infertility, menstrual cycle pattern, type of infertility, hirsutism and ovarian volume did not significantly affect the results of our study. In a study by Amer et al., 2004 they showed that ovulation and pregnancy rates are significantly decreased in patients with increasing duration of infertility (> 3 years), increasing BMI (>35 kg / $\mathrm{m} 2$ ) and marked hyperandrogenism. Statistical analysis showed that the duration of infertility is the most important independent factor which predict the occurrence of ovulation after LOD followed by free androgen index then BMI. However age, the presence or absence of acne, ovarian volume and menstrual cycle pattern did not seem to predict the outcome of LOD in the same study. Proper identification of predictors of success will help in selection of ideal cases for LOD and ideal cases for gonadotrophin therapy and $\operatorname{IVF}^{(22)}$.

In our study there was no significant difference between ovulating and non-ovulating groups as regard LH, FSH and total testosterone level before LOD. However, after LOD the difference was highly significant. In ovulating group (70\% of cases), LH decreased significantly from $(13.1 \pm 1.9)$ before LOD to $(6 \pm$ $0.6)$ after LOD and total testosterone decreased significantly from $(1.04 \pm 0.23)$ to $(0.51 \pm 0.2)$. As regard $\mathrm{FSH}$, it increased significantly from $(6.16 \pm$ $0.34)$ before LOD to $(7.6 \pm 0.8)$ after LOD.

This was the same as reported by Parsanezhad et al., 2003 within $6 \pm 10$ weeks after LOD. In their study in ovulating group, LH decreased significantly from $(16.86 \pm 4.53)$ before LOD to (11.7 6+4.82) after LOD and total testosterone decreased significantly from $(1.18 \pm 0.32)$ to $(0.72 \pm 0.28)$. As regard $\mathrm{FSH}$, it increased significantly from $(6.42 \pm 1.85)$ before LOD to $(7.55 \pm 1.98)$ after $\operatorname{LOD}^{(4)}$.

In a study by Abou Sekkein et al., ${ }^{(23)}$ LH decreased significantly from $(12.96 \pm 2.1)$ before
LOD to $(10.62 \pm 1.8)$ after LOD. FSH decreased insignificantly from $(5.8 \pm 0.4)$ before LOD to $(5.3 \pm 0.51)$ after LOD. In a study by Safdarian $\mathbf{L}$ et al. ${ }^{(24)} \mathrm{LH}$ decreased significantly from (13.23 \pm $0.56)$ before LOD to $(8.61 \pm 0.62)$ after LOD. As regard FSH, it increased insignificantly from (6.62 $\pm 0.41)$ before LOD to $(8.70 \pm 0.52)$ after LOD.

This also was the same as reported by Onofriescu A et al., ${ }^{(25)}$ within 6 weeks after LOD. In their study, LH decreased significantly from $(5.62 \pm 0.33)$ before LOD to $(4.47 \pm 0.3)$ after LOD and total testosterone decreased significantly from $(0.73 \pm 0.16)$ to $(0.66 \pm 0.11)$. As regard FSH, it increased significantly from $(3.95 \pm 0.21)$ before LOD to $(4.64 \pm 0.21)$ after LOD.

In a study by Elmashed $\mathbf{A I}^{(26)}$ LH decreased insignificantly from $(11.7 \pm 1.3)$ before LOD to $(10.8 \pm 1.8)$ after LOD. FSH decreased insignificantly from $(4.2 \pm 1.3)$ before LOD to $(4.1 \pm 1.4)$ after LOD. Total testosterone decreased significantly from $(4.2 \pm 0.4 \mathrm{nmol} / \mathrm{L})$ before LOD to $(2.6 \pm 0.6 \mathrm{nmol} / \mathrm{L})$ after LOD.

In a study by Samy $\mathbf{N}$ et al., ${ }^{(27)}$ LH decreased significantly from $(12.57 \pm 4.28)$ before LOD to $(9.35 \pm 3.12)$ after LOD and total testosterone decreased significantly from $(2.79 \pm 1.6)$ to $(1.98 \pm 1.13)$. As regard FSH, it decreased insignificantly from $(6.34 \pm 2.83)$ before LOD to $(6.33 \pm 2.44)$ after LOD.

The mechanism of action of LOD is the destruction of the androgen-producing stroma in the ovary resulting in decrease in the circulating androgens and also decrease in the circulating estrone (E1) due to decreased peripheral aromatization of androgens. This E1 fall resulted in decreased positive feedback on $\mathrm{LH}$ and decreased negative feedback on FSH at the level of the pituitary, so LH decreases and FSH increases resulting in follicular development. Another theory is the the production of nonsteroidal factors due to ovarian injury resulting in restoration of the normal ovarian- pituitary relationship. The last theory is that injury to the ovarian tissue results in production of certain growth factors, which increase the sensitivity of the ovary to the circulating gonadotrophins resulting in normal follicular growth ${ }^{(20)}$.

In contrast to our study, Tulandi et $\boldsymbol{a l} .{ }^{(28)}$ they did not find a significant difference in hormonal profile before and after LOD. A few studies reported the same LH level long period after $\operatorname{LOD}^{(29,} \mathbf{3 0}$. Also other studies showed nonsignificant difference in testosterone level after $\operatorname{LOD}^{(31,32)}$. The cause for this mostly was the use of different techniques for LOD which was associated with less thermal injury (less number 
of punctures- less duration of application- less dose of electric current).

In non-ovulating group ( $30 \%$ of cases), LOD caused change in LH decreased from (12.5 $\pm 2.1)$ before LOD to $(11.6 \pm 2.4)$ after LOD $\}$, FSH increased from $(5.9 \pm 0.87)$ before LOD to $(6.1 \pm 0.9)$ after LOD $\}$ and total testosterone \{decreased from $(1.08+0.27)$ before LOD to $(0.96 \pm 0.23)$ after LOD $\}$, however, this change was insignificant within the period of follow up (10 weeks).

In our study, the failure rate was $30 \%$. It may be due to less amount of thermal power which is not sufficient to produce the desired effect. But studies showed that minimal amount of thermal energy and even unilateral ovarian drilling is sufficient to produce ovulation. Failure of ovulation may be also due to resistance of the ovarian stroma to the thermal effects of LOD. Another cause may be hyperprolactaenaemia detected in some PCOS patients after drilling. It is very difficult to determine the dose of electric current for each patient undergoing $\mathrm{LOD}^{(33)}$.

In our study, we did not determine the amount of thermal energy according to the ovarian volume or side but the amount of thermal energy was fixed in all patients regardless the ovarian size.

In our study there was no significant difference between ovulating and non-ovulating groups as regard PSV, PI and RI before LOD. However, after LOD the difference was highly significant. In ovulating group (70\% of cases), PSV decreased significantly from $(11.9+1.8)$ before LOD to $(7.44+1.5)$ after LOD. PI increased significantly from $(2.02+0.56)$ before LOD to $(2.98+0.5)$ after LOD. As regard RI, it increased significantly from $(0.75+0.06)$ before LOD to $(0.86+0.05)$ after LOD.

This was the same as reported by Parsanezhad et al. ${ }^{(4)} 6$ - 10 weeks after LOD. In their study in ovulating group, PSV decreased significantly from $(14.04+6.82)$ before LOD to $(12.49+6.32)$ after LOD. PI increased significantly from $(0.98+0.36)$ before LOD to $(1.78+0.72)$ after LOD. As regard RI, it increased insignificantly from $(0.55+0.16)$ before LOD to $(0.71+0.19)$ after LOD.

In a study by Abou Sekkein et al $^{\left({ }^{(23)}\right.}$ PSV decreased significantly from $(15.19+1.76)$ before LOD to $(8.68+0.74)$ after LOD. PI increased insignificantly from $(0.85+0.11)$ before LOD to $(0.9+0.14)$ after LOD.

In a study by Safdarian $\mathbf{L}$ et $\boldsymbol{a l} .^{(24)}$ PI increased significantly from $(2.01 \pm 0.64)$ before LOD to $(2.89 \pm 0.57)$ after LOD. As regard RI, it increased significantly from $(0.76 \pm 0.11)$ before LOD to $(0.84 \pm 0.08)$ after LOD.

The only study that proved that ovarian stromal blood flow increases after LOD was done by Vizer and co-workers ${ }^{(18)}$. In this study LOD was done on both ovaries (40Watts monopolar coagulating current), and 15-20 cautery points were performed at a depth of 5-7 $\mathrm{mm}$ and threedimensional sonography was used to assess the intraovarian blood flow. The defect in this study was the small sample size (10 patients), so this study cannot be used to evaluate the relationship between ovarian stromal blood flow changes and ovulation

In contrast to a study by El Behery et al., 2011 who used three-dimensional (3D) sonography to assess the intraovarian blood flow after LOD in patients with PCOS, they concluded that blood flow within the ovarian stroma was significantly higher in the PCOS women than in the normal women and the blood flow within the ovarian stroma was significantly decreased in the PCOS women after drilling ${ }^{(34)}$.

In non-ovulating group (30\% of cases), PSV decreased insignificantly from $(12+2.48)$ before LOD to $(10+3)$ after LOD. PI increased insignificantly from $(1.92+0.3)$ before LOD to $(2.2+0.3)$ after LOD. As regard RI, it increased insignificantly from $(0.7+0.07)$ before LOD to $(0.8+0.1)$ after LOD.

The results of this study demonstrated that in ovulating group, ovarian stromal blood flow velocity declined significantly after LOD in women with PCOS compared to non-ovulating group in which the decline is insignificant. Also, we detected a rapid fall in blood flow within the ovarian stroma with $\mathrm{LH}$ and total testosterone level within 10 weeks after LOD mainly in ovulating group.

The aetiology of high ovarian stromal blood flow in PCOS patients is not clear up till now. Serum estradiol (E2) may a role in regulation of uterine and ovarian blood flow ${ }^{(35)}$.Greenblatt and Casper ${ }^{(36)}$ proved in their study that E2 level decreases the first day after drilling, reaching the lowest level by day 4 after operation and begin to rise after that. So there is a vague relation between serum E2 levels and ovarian blood flow changes after LOD. Ovarian stimulation with gonadotrophins is followed by significant reduction in vascular impedance to blood flow in the ovarian artery ${ }^{(37)}$, and in arteries around the follicles, in correlation with an increase in the number of follicles and serum E2 concentration ${ }^{(38)}$. Considering these observations and the data reported by Schurz et al. ${ }^{(39)}$ it seems that factors 
other than E2 is the etiology of high ovarian stromal blood flow in PCOS patients.

In a study by Dolz et al., ${ }^{(40)}$ they suggested that the etiology of high ovarian stromal blood flow in PCOS patients is the abnormal timing of LH-dependent prostaglandin release. Bourne and co-workers $^{(41)}$ showed in their study that prostaglandins E2 and I2 are strong vasodilators substances, which increase blood flow within the ovarian stroma.

VEGF is one of the most important factors that regulate angiogenesis in the ovary. Within the ovary, it is produced in the theca cells, granulosa and lutein cells and the interstitial ovarian tissue. Increased ovarian stromal blood flow velocity is most probably due to higher serum concentrations of vascular endothelial growth factor (VEGF) in PCOS women ${ }^{(42)}$.

Ovarian stroma is the source of blood supply to the small preantral follicles. Follicular blood flow increases with growth of primary follicles. Laparoscopic ovarian drilling decreases the number of small and intermediate follicles that usually seen in PCOS, it has the same effect on ovarian stromal tissue ${ }^{(43)}$. So LOD may decrease the ovarian stromal blood flow velocity by its direct thermal effects on ovarian tissue.

Reduction of the increased ovarian stromal blood flow velocity in PCOS may be the cause of altering ovarian steroidogenesis, after $\mathrm{LOD}^{(5)}$.

In our study There was significant negative correlation between total testosterone and PI $(r=$ 0.49 , p. value $<0.01$ ), highly significant negative correlation between total testosterone and RI ( $\mathrm{r}=$ 0.41 , p. value $<0.001)$ and significant positive correlation between total testosterone and $\mathrm{PSV}(\mathrm{r}=$ o.32, p. value $<0.05)$. Also, there was significant positive correlation between FSH and RI $(r=0.32$ p. value <0.05).

Correlation between ovarian stromal blood flow changes and hormonal profile alteration means that variables correlation (for example, decreased testosterone and increased PI and RI) is most probably caused by one factor (thermal effect of LOD).

A very rapid response has been reported following LOD in several studies, with ovulation occurring within 2- 4 weeks and menses within 46 weeks in the responders. Restoration of regular ovulatory cycles occurs in about two thirds of cases ${ }^{(198)}$. In our study menses occurred in 40 patients ( $80 \%$ of cases) during the follow up period (10 weeks) and 10 patients (20\% of cases) did not menstruate during the same period.

In our study we found that 35 cases $(70 \%)$ showed ovulation as evidenced by folliculometry (leading follicular diameter $\geq 18 \mathrm{~mm}$ ) and mid luteal serum progesterone level ( $>5 \mathrm{ng} / \mathrm{ml})$ and 15 cases $(30 \%)$ did not show ovulation as evidenced by lack of menses( 10 cases), poor serial transvaginal ultrasound folliculometry and low mid-luteal serum progesterone level (5 cases). This ovulation rate was less than reported by Parsanezhad et al., $(73.1 \%)^{(4)}$, and more than reported by Abou Sekkein et al., $(69.23 \%)^{(\mathbf{2 3 )}}$ and Amer et al., $(67 \%)^{(44)}$. The cause for this difference in ovulation rate may be due to different techniques of drilling (monopolar or bipolar type of diathermy, Laser or diathermy, duration of electric current application, different number, diameter and depth of punctures and different amount of thermal energy).

In our study pregnancy rate in ovulating group during 6 months of follow up after LOD was $57 \%$ ( $40 \%$ of the whole number of cases in our study). Many studies reported different ovulation and pregnancy rates after laparoscopic ovarian cauterization. Different pregnancy rates between different studies are most probably due to different techniques of LOD, different patient characteristics and different periods of follow up after LOD.

Further researches on a larger sample size are required to detect the relationship between LOD, ovarian stromal blood flow and ovarian steroidogenesis.

\section{CONCLUSION}

PCOS is a common problem in gynecological practice. To manage it, we should at first oriented by its pathophysiology. Management includes lifestyle modification in form of weight loss, exercise and diet control in addition to medications which induce ovulation such as clomiphene citrate and gonadotrophins, or surgical induction of ovulation by laparoscopic ovarian drilling (LOD).

- Advantages of LOD include no need for follicular or hormonal monitoring, no hyperstimulation syndrome due to absence of multiple ovulations. Postoperative adhesions and premature ovarian failure are common problems which may follow LOD.

Mechanism of action of LOD is achieved by destruction of the androgen producing ovarian stroma which in turn leads to decrease in androgen and estrogen levels with restoration of normal hypothalamic and pituitary functions resulting in decrease in $\mathrm{LH}$ and increase in FSH levels. Also, thermal trauma to the ovarian stroma leads to increased resistance to blood flow in ovarian tissue with reduction in ovarian stromal 
blood flow and subsequent restoration of normal blood flow in ovarian tissues. This finally leads to restoration of the normal hypothalamo-pituitaryovarian function and occurrence of folliculogenesis and ovulation.

Finally, we can conclude that laparoscopic ovarian drilling is a good second choice to induce ovulation in patients with PCOS who are clomiphene citrate resistent. Its effect on hormonal profile of the patient and ovarian sromal blood flow can be used to predict the occurrence of ovulation. Significant changes in hormonal profile and ovarian sromal blood flow after LOD is associated with ovulation. However, insignificant changes in hormonal profile and ovarian sromal blood flow after LOD is associated with no ovulation and the patient shows failure to the thermal effect of LOD and should be reevaluated for possibility of using other options for ovulation induction.

\section{REFERENCES}

1-Speroff L, Glass RH, and Kase NG. Anovulation and the polycystic ovary. Clinical gynecologic endocrinology and infertility. 7th ed. Philadelphia(PA): Lippincott Williams \& Wilkins; 2005.p. 465-98.

2-Archer JS, Chang RJ. Hirsutism and acne in polycystic ovary syndrome. Best Pract Res Clin Obstet Gynaecol 2004; 18: 737-54.

3-The Rotterdam ESHRE/ASRM-sponsored PCOS consensus workshop group. Revised 2003 consensus on diagnostic criteria and long term health risks related to polycystic ovary syndrome (PCOS). Fertil Steril 2004;81:1925.

4-Parsanezhad ME, Bagheri MH, Alborzi S, Schmidt EH. Ovarian stromal blood flow changes after laparoscopic ovarian cauterization in women with polycystic ovary syndrome. Hum Reprod 2003; 18: 1432-7.

5-Zaidi J, Campbell S, Pittrof R, Kyei-Mensah A, Shaker A, Jacobs HS, Tan SL. Ovarian stromal blood flow changes in women with polycystic ovaries. A possible new marker for ultrasound diagnosis. Hum.Reprod 1995; 10: 1992-1996.

6-Bostancia MS, Sagsozb N, Noyanb V, Yucelb A, Gorenc K. Comprasion of ovarian stromal and uterine artery blood flow measured by color Doppler ultrasonography in polycystic ovary syndrome patients and patients with ultrasonographic evidence of polycystic ovaries. J Clin Gynecol Obstet 2013;2(1):2026.

7-Engmann L, Sladkevicius P, Agrawal R, Bekir J, Campbell S, Tan SL. The pattern of changes in ovarian stromal and uterine artery blood flow velocities during IVF treatment and its relationship with outcome of the cycle. Ultrasound Obstet Gynecol 1999; 13: 26-33.

8-Amin M, Abdel-Kareem O, Takekida S, Moriyama T, Abdel-aal G, Maruo T. Up-date management of non responder to clomiphene citrate in polycystic ovary syndrome: minireview. Kobe J Med Sci 2003; Vol. 49, No. 3, pp. 59-73.

9-Lord JM, Flight IH, Norman RJ. Metformin in polycystic ovary syndrome: systematic review and meta-analysis. BMJ 2003;327:951-953.

10-Palomba S, Orio Jr F, Nardo RJ. Metformin administration versus laparoscopic ovarian diathermy in clomiphene citrate resistant women with polycystic ovary syndrome: a prospective parallel randomized double -blind clinical trial. $J$ Clin Endocrinol Metab 2004;89:4801-4809.

11-Bayram N, Van Wely M, Kaaijk EM. Using an electrocautery strategy or recombinant follicle stimulating hormone to induce ovulation in polycystic ovary syndrome: randomized controlled trial. BMJ 2004;328:192-195.

12-Farquhar C, Lilford RJ, Marjoribanks J. Laparoscopic "drilling" by diathermy or laser for ovulation induction in anovulatory polycystic ovary syndrome. Cochrane Database Syst Rev 2005;20: CD001122.

13-Amer S, Li TC, Gopalan V, Ledger WL, Cooke ID. Long term follow up of patients with polycystic ovary syndrome after laparoscopic ovarian drilling: clinical outcome. Hum Reprod 2002;17:2035-2042.

14-Liguori G, Tolino A, Moocia G, Scognamiglio G, Nappi C. Laparoscopic ovarian treatment in infertile patients with polycystic ovary syndrome (PCOS): endocrine changes and clinical outcome. Gynaecol Endocrinol 1996;10:257-264.

15-Gjonnaess H. Polycystic ovary syndrome treated by ovarian electrocautery through the laparoscope. Fertil Steril 1984;41:20-25.

16-Amin AF, Abdel-aal DE, Darwish AM, Meki AR. Evaluation of the impact of laparoscopic ovarian drilling on Doppler indices of ovarian stromal blood flow, serum vascular endothelial growth factor and insulin like growth factor I in women with polycystic ovary syndrome. Fertil Steril 2003; 79:938-41.

17-Wu MH, Huang MF, Tsai SJ. Effects of laparoscopic ovarian drilling on young adult women with polycystic ovarian syndrome. $J$ Am Assoc Gynecol Laparosc 2004; 11: 18490. 
18-Vizer M, Kiesel L, Szabo I, Arany A, Tamás $\mathrm{P}$, Szilágyi A. Assessment of threedimensional sonographic features of polycystic ovaries after laparoscopic ovarian electrocautery. Fertil Steril 2007; 88: 894-9.

19-Parsanezhad ME, Zarei A, Sayadi M, Jaafarzadeh A, Rajaeefard A, Frank V, Schmidt EH. Surgical ovulation induction in women with polycystic ovary syndrome: A systematic review. Iran J Med Sci 2009; 34(4): 225-241.

20-Amer S. Laparoscopic ovarian surgery for polycystic ovarian syndrome. In: Bonnar $\mathbf{J}$ and Dunlop W (eds). Recent advances in obstetrics and gynecology, $24^{\text {th }}$ edn. Bell and Bain, Glasgow, UK.2008; PP 227- 243.

21-Roy KK, Baruah J, Sharma A, Sharma JB, Kumar S, Kachava G, Karmakar D. A prospective randomized trial comparing the clinical and endocrinological outcome with rosiglitazone versus laparoscopic ovarian drilling in patients with polycystic ovarian disease resistant to ovulation induction with clomiphene citrate Arch Gynecol Obstet (2010) 281:939-944

22-Amer S, Li TC, Ledger WL. ovulation induction using laparoscopic ovarian drilling in women with polycystic ovary syndrome: predictor of success. Hum Reprod 2004; 19: 1719-1724.

23-Abou Sekkein IA, Hassanin US, El-Heni MA, Kolkailah MA. Assessment of ovarian stromal blood flow in polycystic ovary. Sci. Med J. ESCME, Vol. 14,No.1.Jan.2002.

24-Safdarian L, Eslamian L, Adineh M, Aghahoseini M, Aleyasin A, Saidi H. Impact of laparoscopic ovarian electrocautery on Doppler indices of ovarian stromal blood flow in women with polycystic ovary syndrome. Acta Medica Iranica,2008 46(3): 203-206.

25-Onofriescu A, Dragos Nemescu D, Onofriescu M, Carmen Vulpoi C. Laparoscopic ovarian drilling for polycystic ovarian syndrome. TMJ 2012, Vol. 62, No. 1 - 2.

26-Elmashed AI. Impact of laparoscopic ovarian drilling on Anti-Mullerian hormone levels and ovarian stromal blood flow using threedimensional power Doppler in women with anovulatory polycystic ovary syndrome. Fertil Steril .2011;95:2342-6.

27-Samy N, Afify M, Hassan AK, Bakr N, Abdl Maksoud N, Saeed M. Serum vascular endothelial growth factor in polycystic ovary syndrome and its relation to ovarian drilling. International Journal of Toxicological and
Pharmacological Research. 2014; 6(4): 123127.

28-Tulandi T, Saleh A, Morris D, Jacobs HS, Payne NN, Tan SL. Effects of laparoscopic ovarian drilling on serum vascular endothelial growth factor and on insulin responses to the oral glucose tolerance test in women with polycystic ovary syndrome. Fertil Steril. 2000 Sep;74(3):585-588.

29-Szilagyi A, Rossmanith W, Csermely T. Changes in circulating hormone levels after ovarian wedge resection in patients with polycystic ovary syndrome. Arch Gynecol Obstet 1990; 248: 31-5.

30-Asada H, Kishi I, Kaseda S. Laparoscopic treatment of polycystic ovaries with the holmium: YAG laser. Fertil Steril 2002; 77: 852-3.

31-Farhi J, Soule S, Jacobs HS. Effect of laparoscopic ovarian electrocautery on ovarian response and outcome of treatment with gonadotropins in clomiphene citrate- resistant patients with polycystic ovary syndrome. Fertil Steril 1995; 64: 930-5.

32-Fukaya T, Murakami T, Tamura M. Laser vaporization of the ovarian surface in polycystic ovary disease results in reduced ovarian hyperstimulation and improved pregnancy rates. Am J Obstet Gynecol 1995; 173: 119-25.

33-Togar T. Laparoscopic treatment of PCOS it is a time to relinguesh procedure. Fertil.steril 2003 80(2)241-5.

34-El Behery MM, Diab AE, Mowafy H, Ebrahiem MA, Shehata AE. Effect of laparoscopic ovarian drilling on vascular endothelial growth factor and ovarian stromal blood flow using 3-dimensional power Doppler. International Journal of Gynecology and Obstetrics 112 (2011); 119-121.

35-Zaidi J. Blood flow changes in the ovarian and uterine arteries in women with normal and polycystic ovaries. Hum. Fertil.2000 (Camb.), 3, 194-198.

36-Greenblatt EM, Casper RF. Endocrine changes after laparoscopic ovarian cautery in polycystic ovarian syndrome. Am. J. Obstet. Gynecol.1987, 156, 279-285.

37-Deutinger J, Reinthaller A, Bernaschek G. Transvaginal pulsed Doppler measurement of blood flow velocity in the ovarian arteries during cycle stimulation and after follicle puncture. Fertil. Steril.1989, 51, 466-470.

38-Weiner Z, Thaler I, Levron J, Lewit N, Itskovitz-Eldor J. Assessment of ovarian and uterine blood flow by transvaginal colour 
Doppler in ovarian-stimulated women: correlation with the number of follicles and steroid hormone levels. Fertil. Steril.1993, 59, 743-749.

39-Schurz B, Schon HJ, Wenzl RE, Huber J, Reinold E. Endovaginal Doppler flow measurements of the ovarian artery in patients with a normal menstrual cycle and with polycystic ovary syndrome during in vitro fertilization. J. Clin. Ultrasound.1993, 21, 1924.

40-Dolz M, Osborne NG, Balnes J, Raga F, AbadVelasco L, Villalobos A, Pellicer A, BonillaMusoles F. Polycystic ovary syndrome: Assessment with colour Doppler angiography and three-dimensional ultrasonography. J. Ultrasound Med.1999, 18, 303-313.

41-Bourne TH, Reynolds K, Waterstone J, Okokon E, Jurkovic D, Cambell S. Paracetamol-associated luteinized unruptured follicle syndrome: effects on intrafollicular blood flow. Ultrasound Obstet. Gynecol.1991, $1,420 \pm 425$.
42-Ernest Hung Yu Ng, Carina Chi Wai Chan, William Shu Biu Yeung, Pak Chung Ho. Comparison of ovarian stromal blood flow between fertile women with normal ovaries and infertile women with polycystic ovary syndrome. Human Reproduction. 2005, Vol.20, No.7 pp. 1881-1886.

43-Liguri G, Tolino A, Moccia G, Scognamiglio G, Nappi C. Laparoscopic ovarian treatment in infertile patients with polycystic ovarian syndrome (PCOS): endocrine changes and clinical outcome. Gynecol. Endocrinol.1996, 10, 257-264.

44-Amer S, Li TC, Cooke ID. A prospective dosefinding study of the amount of thermal energy required for laparoscopic ovarian diathermy. Human Reproduction.2003 Vol.18, No.8 pp. 1693-1698. 